\title{
Economic Aspects of Environmental Accounting
}

\author{
Roefie Hueting $(*)$
}

\section{Introduction}

On the initiative of the United Nations Enviroment Programme (UNEP), a working group on environmental accounting was formed in 1983. Since then four workshops on enviromental accounting have been held, organized by the World Bank. The participants consisted of experts in the field of enviromental accounting and representatives of developing countries.

The working group was set up against the following background. The economic policy of developing countries focusses to a high degree, maybe even more so than that of industrialized countries, on the growth of the national income. As a result of this one-sided orientation the environment and natural resources are depleted at a high rate, while it is exactly these countries that depend on these in a great measure. The working group is unanimous in its opinion that the present-day course of affairs will endanger a sustainable development in the long run. They are also in agreement that the main data that serve as rule of conduct in the decision-making practice, viz. mutations in the level of the national income (computed-according to the official conventions) and the results of cost-benefit analyses (as usually applied in daily practice), are incomplete and therefore give wrong signals for arriving at a sustainable development.

Ideally there are two ways to counterbalance this: on a micro-scale, the incorporation beforehand of depletion and degradation and the future adverse affects of these in cost-benefit analyses of separate projects (notably projects financed by the World Bank); and on a macro-scale the incorporation of these losses in the System of National Accounts (SNA). In addition the incorporation of environmental data in economic models could serve as valuable information for decisions on the environment. This article, which is a revision of a paper prepared for the working group, considers whether, and if so to what extent, it is possible to provide the desired information.

For that purpose it will first be explained what arguments form the basis for regarding the environment as an integral part of the economy. The observations given in this section represent the theoretical foundation for the practical suggestions regarding environmental accounting in the subsequent sections.

Next it is investigated to what extent it is possible to link environmental and resource data to the SNA. This is probably the most important subject of environmental accounting, above all for the developing countries. Firstly, because national economic policy is directed to a large extent towards the trend of national income. Secondly, because in most developing countries the possibilities of economic planning with aid of econometric models are very limited.

(*) Central Bureau of Statistics, Holanda 
The incorporation of environmental factors in CBA's is also discussed. The application of discount rates receives special attention. This point is of particular importance in individual development projects, such as the projects in Africa, Asia and South America financed by the World Bank.

Afferwards the most advanced part of environmental accounting is considered: the inclusion of environmental factors in economic models. This is especially important wiht regard to estimation of the effects of environmental messures at the level of production and employment. Although most developing countries do not have the availability of sufficient data to perform such excercises, this subject is nevertheless briefly discussed here. The principal reason for this is that the results of a model elaborated in the Netherlands confirm the theory that under the most logical conditions environmental conservation creates jobs. This finding seems of great importance to the developing countries, which after all have to do with a highly vulnerable environment and a great surplus of labour.

A justification for including environmental factors in the SNA, CBA's and models is given.

Finally a brief enumeration ir made of the special difficulties of using environmental accounting in developing countries.

\section{An approach to the environment as an integral part of the economy}

The practice of political decision-making often proceeds from the completely incorrect idea that economics is confined to the production and distribution of goods and services. Via the market mechanism these acquire a price that may be regarded as an indication of their marginal utility. With the aid of this datum weighing takes place in the decision-making. Entirely in the spirit of this reasoning, top priority is given in the economic policy of every country in the world to increasing production, as measured in national income. In this view - again wrongly - growth of production is identical with economic progress. Of course the level of production is a very important factor influencing welfare, particularly in developing countries. There are, however, also other factors that affect welfare. These will be enumerated below.

I cannot avoid the following impression. Many environmental economists who reject this traditional wag of thinking are nevertheless unable to dissociate themselves from it entirely. In the practice of theorization and research, this leads to attempts and recommendations to integrate scarce environmental goods in market terms in the SMA, in Cost-Benefit Analyses (CBA) and in economic models. Although these attempts are useful, of course, they can succeed to only a small extent, because for scarce environmental goods shadow prices that are directly comparable with the prices of goods produced for the market can be constructed only exceptionally. The elimination cost curve of environmental functions (the supply curve) can be constructed in principle. But the demand curve for environmental functions can be construed only by way of exception, because the urgency of the needs for the present and future availability of environmental functions (in comparison to that of market goods) in most cases cannot be derived either directly or indirectly from market or other behaviour, nor, in many cases, can interview techniques yield defensible results, especially when the future is involved; the preferences for saving the environment in the long run can only be expressed to a limited degree in market data like compensation costs and financial damage (Hueting, 1980a).

Of course, in itself it is most useful, as far as possible, to include the environment in market terms in CBA's, the SNA and models. The present author has also made a contribution to that(1). But the great danger here is that policiticians and the public come to interpret the relatively very small part of scarce environment goods that can be valued in terms of money as the only part of the environment that is of importance in decision-making. This is the well-known pars pro toto hazard: a part is regarded as the whole.

Therefore, it would seem better to allow politicians and the public to become familiar with the idea that the economic aspect of the environment forms an essential and integral part of economics, irrespective of whether it is valuated in monetary terms or not. The simple reasoning required for this, which is nothing more than a description of everyday reality, amounts in brief to the following(2).

Economics boils down to making choices among scarce means that satisfy human wants (the subject matter of economics). The satisfaction of wants evoked by dealing with scarce means is called welfare. In their dealings with scarce means, people try to attain the highest possible welfare (satisfaction of wants) - the opposite is nonsensical. The level of welfare attained cannot be measured directly. But the factors 
that influence welfare can be, though in non-monetary units. A distinction can be made between at least seven factors influencing welfare:

1. The package of produced goods and services.

2. The scarce environmental goods in the broad sense, i.e. inclusive of space, energy, natural resources, plant and animal species.

3. Time or leisure time.

4. The distribution of scarce goods (or income distribution).

5. Working conditions, i.e. the conditions in which scarce goods are acquired.

6. Employment or the degree of free choice between working and other ways of spending time.

7. The safety of the future insofar as this depends on our dealings with scarce goods.

Much more can be said than is done here about the relation between these factors and welfare. For instance, the relation between employment and welfare is a complicated one. After all, work has two sides to it. It is a sacrifice, but also a fulfilment.

In everyday practice these factors are constantly weighed against one another, either directly by ourselves or by political decision-making. This is quite easy to understand in the case of scarce goods (produced goods, scarce environmental goods and time). For there, ceteris paribus (e.g. the state of technology), the simple truth always applies by definition: more of the one means less of the other. But with regard to the other factors too, conflicts often occur in which a choice has to be made. Thus, besides improvement of the environment and more time for leisure, improvement of working conditions or greater equality of income way also be at the expense of the volume of production, at least in the short term; reduction of involuntary unemployment may require sacrifice of income or acceptance of less agreable work; exhaustion of the environment may be at the expense of the safety of the future. Seen from the point of view of those who choose (citizens or politicians) there is thus a close connection between all the factors influencing welfare.

L. Robbins states in An Essay on the Significance of Economic Science (see note 2): "There are no economic ends as such; there are only economic problems involved in the achievement of ends". When, therefore, health or justice or something else that people want to accomplish is accepted as a (human) end and something has to be sacrified to achieve that end, economic choice is involved.

Following this reasoning, which is universally accepted in modern welfare theory, economic growth can mean nothing more than an increase in welfare. The identification of growth of production with increase in welfare gives rise to a compelling but totally incorrect suggestion, namely that things go well, economically speaking, solely when production increases. When society attaches greater weight to conservation of the enviroment and to the production dependent on that in the future (thus to a safer future) than to growth of production, a policy aimed at this is, from the economic point of view, the only responsible policy, even if this is at the expense of the highest rate of potential growth of production attainable at this moment.

The above text has not been confined to the economic aspect of the environment in order to make the conclusions clearer. Shadow prices for environmental functions can be constructed only exceptionally, but the extent of their availability can be expressed in other units than money; in addition, the present and future importance of environmental functions can be described, as also the consequences of their impairment; the costs of conservation (the elimination costs) can moreover always be estimated in principle (Hueting, 1980b). The same can be said, mutatits mutandis, about the other factors determining welfare. Income distribution, employment, working conditions and leisure time are also expressed in other units than money. Further to that, just as in the case of environmental fuctions, cost estimates can be made: what is, ceteris paribus, the sacrifice of produced goods entailed by more leisure, better working conditions, more equal distribution or part-time work?

The conclusion to which the reasoning leads is the following. In decisions on a factor influencing welfare, for instance increase of production or conservation of environmental functions, the effects on the other factors must be estimated. In doing so the prices of produced goods must be left out of consideration for the sake of accurate weighing. For, if we confine ourselves for simplicity's sake to production (plus consumption) and environment, the price of a produced good gives only and indication of its marginal utility in respect of other marketable goods but does not provide the slightest indication of its utility in respect of unpriced goods, in this case the environmental functions disturbed in production and consumption. 
This can perhaps be futher clarified as follows. If production and consumption of produced goods take place at the expense of environmental goods that are useful to man, the (market) value a has to be reduced by the unknown value $\mathrm{x}$ of the environmental functions. Thus the produced goods have in fact the unknown value $a-x=y$. Since the shadow price $x$ cannot be constructed, the value $y$ of the produced goods can equally not be construed. No economist can prove that the value of produced goods is a priori higher than the value of an environmental function.

In the above the environment is implicitly interpreted as a collection of environmental functions. Below, the reasoning on which this has been based will be briefly explained(3).

For an economic approach the environment can best be defined as man's physical surroundings on which he is dependent in all his doings (production, consumption, breathing, leisure, etc.). Within this environment a number of possible uses - environmental functions - can be distinguished. When the use of an environmental function by an activity is at the expense of the use of another (or the same) function by another activity, loss of function occurs; losses of function form costs. We call this competition between functions and make a distinction between qualititative, spatial and quantitative competiton. Qualitative competiton amounts broadly speaking to pollution: the use of the environmental function "dumping ground for waste" is at the expense of other functions. There is as it were an intermediate step. An activity introduces an agent (for instance a chemical, heat, noise) into the environment, as a result of which the quality changes; this may disturb other use or render it impossible. In the case of spatial and quantitative competion the amount of space or matter is insufficient to meet the existing wants for it. By activity is also meant sparing the function "natural environment" on account of its present and future utility to man.

This approach is much broader than the traditional approach to the environment as a pollution problem that can be solved by building treatment plants. Tracing the competiton between functions exposes the conflicts. Intensification and increase in scale of agriculture and fragmentation of space by roadbuilding and suburbanization thus logically fall under the environmental problem by their effect on plant and animal species (spatial competition with the function "natural environment").

Competition between functions may occur in all kinds of forms. But in by far the majority of cases one can speak of use of the environment by producing and consuming activities at this moment which is at the expense of other desired use or (with a certain degree of probability) of future possible uses. We have now, roughly speaking, reached a situation in which the use of an environmental function is always at the expense of one or more other functions (now or in the future). Of course our environment is material, as are the things that we produce and consume with the aid of it, whether these are wheat, music, medical aid or books.

In this situation the subject matter of economics can be described as the study of the problems of choice that occur when arranging the dead and living matter of our surroundings in accordance with man's wishes. Such a definition does justice to the fact that the environment is the basis of our existence, the foundation of our production and consumption and, in view of the competition between functions, finite.

\section{Suggestions for linking environmental and resource data to the System of National Accounts (SNA)}

The linking of environmental and resource data to the System of National Accounts (SNA) is of particular importance, as the outcome of the SNA calculations has a significant bearing on the formulation of national economic policy and therefore on the state of the environment.

The problem of incorporating environmental factors in the System of National Accounts fits firstly into the well-known debate concerning the question whether national income is or is not an indicator of welfare and secondly into the familiar problem of double counting.

Concerning the first point, it follows from what has been said in Section 2 that national income is in principle (that is: apart from problems of double counting) an indicator of the level and growth of the production of goods and services. National income is not, of course, and indicator of welfare, nor have the pioneers in this field ever claimed that is was (Hueting, 1980a). As has been said earlier, the identification of production growth with economic progress gives a one-sided and distorted picture of reality, of which in practice the environment is the victim. This has above all a negative effect on the prospect of a safer future through the well-known hazards of overshoots and collapse, which may rightly 
be feared if production continues to grow in accordance with the present pattern(4). In this way the identification of production growth with economic progress hampers the transition to a policy aimed at a sustainable economy.

The desire to express the course of welfare over time is understandable. However, we should not become bogged down in these attempts. The various factors determining welfare cannot be placed under a common denominator (see above). Moreover, different people attach different weights to the factors. In addition to extra difficulties for measurement, this also entails the drawback of interpersonal comparison of utility. For all these reasons a balance cannot be struck in one simple figure. It is therefore recommended that the development of the factors over time be statistically mapped, each in units suited to it. Together with cost data and a description of the significance of the factors, information can thus be supplied for economic policy, notably for economic environmental policy (see above). A first step in this direction can be found in a recent publication by the National Accounts Division of the Netherlands Central Bureau of Statistics, in which the present author has also been involved(5).

As for the second point, there is an extensive literature on the question of double counting in national income. A survey of it can be found in: Hueting, 1980a. There is a fairly considerable measure of agreement on the following points.

The first more advanced compilations of national income took place in the Thirties and Forties. Since in those days there was no serious environmental decay as yet, national income could at that time serve as an indicator of the extent to which society has succeeded in increasing the availability of scarce goods. As a result of the loss of scarce environmental goods occurring around 1950 at an accelerated pace, national income can now no longer serve as an indicator of the availability of scarce goods. Moreover, through this development, the well-down problem of duplication (double counting) has strongly increased. S. Kuznets already pointed to this at an early stage (Kuznets, 1947 and 1948).

The double counting refers to a situation where for instance expenditures on the restoration of environmental functions are entered in the SNA as final deliveries. They should however be seen as intermediate deliveries (costs) and entered as such. The reason for this is that restoration measures only reestablish the original situation of the environment, without bringing about an increase in the real amount of goods and services available.

Both of the above problems, firstly that on the welfare aspect of national income and secondly the existence of double counting, have a direct bearing on attempts to link environmental data to the SNA. The ideal linking to the SNA of environmental factors could be brought about if the losses of functions and the depletion of recources could be entered as a final delivery at the moment it is undertaken. Such a linking would to a large extent restore the national income as an indicator of one of the factors that influence welfare, since the greater part of the double counting is probably related to environmental expenditures.

It is indicated above however, that such a procedure is not possible. The construction of shadow prices that would effectively reflect the value of environmental functions and resources is possible only in situations that rarely arise.

A partial solution to this problem, with which most authors in the field agree, is the use of an SNA incorporating elimination costs (costs of measures that remove a polluting agent at the source, as a result of which the environmental functions at stake are wholly or partly restored), restoration costs (such as the cleaning of poisoned soil), compensation costs (such as additional facilities for the preparation of drinking water etc.) and financial damage as expenditures by purpose. Such a solution is recommeded by the Statistical Commission and Economic Commission for Europe (ECE, 1973) and in the publication cited under note 5. The adoption of such a solution would be a first step in the right direction.

There are certain advantages and drawbacks in the use of this procedure. The advantages are as follows:

1. Isolation of the above-mentioned environmental items allows the possibility of a better insight into the interactions between production and environmental deterioration. It can also lead to a more accurate picture of the availability of goods and services produced by private enterprise and the authorities. For, the users of the SNA statistics can then determine on the strength of arguments whether, and if so to what extent, national income is increasing.

2. Such a procedure would also facilitate the linking of environmental expenditures to satellite accounts in which the result of these expenditures can be registered in physical terms $(6)$. This amounts as it were to a cost-effectiveness analysis on a macro level. 
The disadvantages associated with this approach are as follows:

1. It should be apparent that the connection between environmental factors and the SNA can be made only as far as measures are actually taken that lead to expenditures or as far actual financial damage occurs. All losses of environmental functions and depletion of resources that do not lead to elimatory, comensatory or other financial outlay are not reflected in the SNA (as shadow prices cannot be construed for these losses). This is particulartly relevant in the case of environmental deterioration that may decrease the level of scarce environmental resources available for production and consumption for future generations.

2. Opportunity costs of different production and consumption patterns can mostly not be derived statistically. This means that environmental measures that involve opportunity costs are not reflected in the SNA. To give just one example, the opportunity costs involved in a decision not to build a road through an area with a fragile soil structure, to prevent erosion, cannot explicitly be stated in statistical terms. This is due to the practical problems involved in detecting all such decisions and in determining whether such decisions have been made with regard to environmental considerations rather than with regard to other criteria such as lack of funds.

The conclusion of this is that a linking of environmental factors to the SNA is only partially possible. This introduces the pars pro toto problem: part of the information is conceived as the total environmental effect. Such an approach could therefore be misleading.

However, as long as the drawbacks of the above approach are kept in mind, there is every reason to pursue such a procedure. For, firstly, it increases the availability of information on the relationship between production and environment and secondly, all the possibilities of deducing environmental statistics in physical terms still remain.

A recent experience has brought the present author to the insight that it might be advisable for practical reasons still to make an effort to incorporate the decline of the environment in the SNA to a further extent than only the expenditure on measures that are actually taken and financial damage that has actually occurred. In 1986 he visited Jakarta by request of prof. dr. Emil Salim, Minister of Population and Environment of Indonesia, who told him that he urgently needs a macro-environment and resource indicator to supplement the indicator of the production, viz. the national income. After an exposé of the difficulties around the construction of shadow prices and the possibilities of using physical units, mr. Salim insisted on an indicator in monetary terms, even if such an indicator is not theoretically sound, because, according to him, only such an indicator would count in politics.

The author then proposed to elaborate the idea of computing an indicator on the basis of the expenditure on measures required to meet physical standards for the availability and quality of environment and natural resources, set by the Indonesian government; the standards could be based, for instance, on the requirement of a sustainable economic development. Mr. Salim replied that the Indonesian government is in principle prepared to set such standards and asked the author to elaborate the method in a report and to consult the Indonesian institutes which could bring it into practice.

He then wrote the report, including the design of a co-ordinated set of tables in which the information required to arrive at the indicator for the case of erosion would fit (Hueting, 1986). Working on the report he became convinced that the method could be useful, provided the results are openly presented with the pros and cons inherent to the method, as mentioned in the report. The experience in Jakarta illustrates the importance of the national income figures for political decisions and the necessity to qualify or correct them.

\section{The incorporation of environmental factors into cost-benefit analyses (CBA's); the application of discount rates}

Cost-benefit analysis (CBA) becomes important in relation to environmental accounting as it is the major method employed in the evaluation of individual projects in the field of development and environment.

In cost-benefit analyses the present value of the future costs and benefits of a project is calculated by the well-known formula:

$$
N P V=\frac{B_{1}-C_{1}}{1+r}+\frac{B_{2}-C_{2}}{(1+r)^{2}} \ldots \ldots+\frac{B_{n}-C_{n}}{(1+r)^{n}},
$$


where NPV $=$ net present value

$$
\begin{aligned}
& \mathrm{B}=\text { monetary benefits in year } \mathrm{n} \\
& \mathrm{C}_{\mathrm{n}}=\text { monetary costs in year } \mathrm{n} \\
& \mathrm{r}_{\mathrm{n}}=\text { discount rate }
\end{aligned}
$$

The formula originates from business economics, where it is used for separate investment projects for a normal period for commercial investments. In these cases the interest $r$ can be interpreted as the compensation for the sacrifice that is made for forgoing present consumption and for running risks. Partly because of this, interest is a help in the allocation of the factors of production in a market economy, without the intervention of bureaucracy. The interest can be paid out of the increase in productivity (i.e. from the greater production) that is attained when the investment has the desired success (pays off). If all goes well, against the sacrifice of lower consumption at the moment of borrowing there is the advantage of higher consumtpion in the (near) future.

Af first sight it seems as if, mutatis mutandis, a similar reasoning can be set up for environmental measures. The interest on investment in environmental conservation may be interpreted as compensation for the sacrifice of lower consumption at the moment of borrowing for the sake of preserving consumption in the future; B expresses the benefits of this. However, when a value has to be entered for B and $\mathrm{r}$ in environmental measures, the following difficulties occur.

The benefits of environmental measures consist of prevention of the loss of environmental functions. Consequently, in order to establish the extent of this loss, we have to know the shadow price of environmental functions. And in most cases this cannot be found (see first section). Only insofar as the loss of function leads to compensatory measures or causes financial damage can sums of money be entered for B. This is only very partially possible, as we have already seen. Entering a value for B is a collective (political) decision that must be based on a description of the utility of the environmental functions in question, a description of the consequences of loss of function and the elimination costs (see first Section and, for a more extensive argumentation, Hueting, 1980a).

A similar difficulty occurs in entering a value for $r$. The reasoning for $r$ in environmental measures is as it were the mirror image of the reasoning for B. Interest in environmental projects is a compensation for the sacrifice of present consumption for the sake of preserving future consumption (in the broad sense: the use of air for physiological functioning and the conservation of plant and animal species and the life support functions dependent on these etc. also come under it). Because environmental functions are collective goods, the height of the interest rate reflects the community's preference for a safer future (the avoidance of overshoots and collapse that impair future possibilities of consumption) in respect of consumption at this moment; the period involved in effects on the environment is in most cases by far much longer than in commercial investments. In the application of the NPV formula in the sphere of business economics (i.e. with market goods), individual subjects (citizens or institutions) receive compensation from other subjects. In the case of completely collective goods such as the environment (non-market goods) the whole community is involved: nobody gives compensation to anyone else: it is jointly decided whether the sacrifice of present comsumption for the sake of the future must be made. A low value of $r$ then means that a safer future is held in high esteem, and vice versa. A value of $r$ approaching zero means a value of the NPV approaching infinite and expresses the fact that the community is prepared to pay the price $\mathrm{C}$ for conserving the availability of the environmental functions at stake, now and in the future (assigning to B a value approaching infinite has the same significance).

We cannot measure the urgency of the need for a safer future (see first Section and Hueting 1980a). Only the following may be remarked about this. Man derives part of the meaning of existence from the company of others. These others include in any case his children and grandchildren. The prospect of a safer future is therefore a normal human need, and dimming of this prospect has a negative effect on welfare.

The conclusion of the above reasoning is clear. Is most cases the NPV formula is meaningless for environmental measures. Making use of it wrongly gives the decisions the aureole of objectivity, whereas in fact completely subjective figures are entered whose correctness cannot be proved. Moreover, the mistake is occasionally made of entering the nominal interest for $r$ and real sums of money (dollars from the base year) for B and C. Part of the interest rate is compensation for inflation. And therefore B, C and $r$ in future years must all be expressed either in nominal (i.e. inflated) units or in real units (i.e. corrected for inflation). 
An exception is formed by those cases in which the preferences for the environmental functions involved can be fully derived from market data like compensation costs and financial damage (see first Section), while the effects on the environment do not surpass the normal period for commerrcial investments (under these conditions there is no objection to using the market interest as a discount rate). In some cases the effects on the environment can be partly derived from market data. It is then advisable, of course, to make the effort to obtain these data, because by this the range on which decisions have to be made on the basis of non-monetary data is decreased(7).

The following suggestion may be made for giving additional information in monetary terms on behalf of measures for environmental conservation. In some cases it is possible to make an estimate of the costs of restoration of environmental functions at stake. This amount can be interpreted as a measure of the risk run by the loss of those functions.

Awareness of the meaninglessness in most cases of the NPV formula for environmental measures can remove a major stumbling block in the way of a good environmental policy.

As an alternative approach to evaluation, cost-effectiveness analysis is often employed. In this approach the effect of the measures taken to prevent harmful environmental impacts or to restore environmental damage (both in money) is measured in physical terms. This avoids the dangers of the NPV formula and is in line with the rest of the suggestions made in this paper.

\section{Estimating the effect of environmental policy on the level of production and employment by incorporating environmental factors in economic models}

The inclusion of environmental factors in economic models can be considered as the most advanced part of environmental accounting. Modeling is especially important with regard to estimation of the effects of environmental measures at the level of production and employment. Although most developing countries do not have the availability of sufficient data to perform such exercises, this subject is nevertheless briefly discussed here. The principal reason for this is that the results of a model elaborated in the Netherlands confirm the theory that under the most logical conditions environmental conservation creates jobs. This finding seems of great importance to the developing countries, which after all have to do with a highly vulnerable environment and a great surplus of labour.

The proposition thet environmental conservation is at the expense of employment is at present probably the biggest stumbling block to a good environmental policy. However, this proposition ignores the simple truth that environment is a scarce good; to obtain or maintain it, factors of production have to be employed. In the industrialized countries $80 \%$ to $90 \%$ of national income goes to the factor labour. This percentage is probably even higher in developing countries. The same amount of production requires more labour with environmental conservation than without(8). However, the labour is employed for nonmarket goods. And since wage is nothing more than a claim to produced goods, environmental measures amount to reduction of the (growth of the) wage rate, with a given package of goods and services produced by the government. The conflict is not between environment and employment but between production (plus consumption) and environment, whereby expenditure on treatment and the like is regarded as costs (see Section on suggestions).

This proposition has been confirmed in a scenario study recently performed for the Dutch economy over the period 1980-2000. In this study a number of scientific institutes first formulated the conditions with which activities must comply in order to stay within certain environmental standards regarding pollution and the conservation of plant and animal species. Then the costs of this were estimated. Finally, with the aide of an econometric model, the consequences were estimated for notably the level of production and employment.

On the basis of the reasoning given above, the costs of the measures are defrayed by charges levied on products (on the domestic market) of polluting activities both at home and abroad. The products therefore undergo a real price increase. For the sake of the effect on employment, wages are not compensated for this. This method obviates impairment of the competitive position on both the domestic market (by products from abroad) and foreign markets. Together with the adjustment to render permanent the positive effect of environmental measures on employment. At the same time the method prevents the flight of polluting activities abroad, for instance to developing countries. 
Through the pay-off effect as a result of the considerable reduction in unemployment, the negative effect of the environmental measures on the level of production is alleviated (this pay-off effect may be expected everywhere, for unemployment is worldwide). But a comparison with a situation without environmental measures shows that growth of production is considerably less with environmental measures than without. A description of the scenario study with a summary of the results may be found in the publication cited under note 4 .

The penetration of this information (inter alia by the perfomance of similar studies in other countries or regions) will remove a major stumbling block in the way of a good environmental policy: under the most logical conditions environmental conservation creates considerable permanent employment; the sacrifice consists of a reduced growth of production at this moment; the risks of overshoots and collapse in the future are lessened as a result (this is the essence of a sustainable economy).

\section{Justification of the inclusion of environmental factors in the SNA, CBA's and models}

Most of the arguments for the inclusion of environmental factors in the SNA, CBA's and models have already been stated in previous sections, notably in the first. They boil down to the observation that, in spite of rapidly progressing environmental deterioration, economic policy keeps concentrating on a short-term increase in production. Due to the real threat of overshoots, this endangers long-term production and consumption possibilities. Since the recovery of environmental losses usually requires considerably more effort than the prevention, the risks for future generations are thus increased. The aim of environmental accounting is actually nothing more than the provision of information for the transition to a policy aimed at a sustainable economy.

The following proposition is often put forward against this: production should, in fact, be increased in order to create scope for environmental measures. This proposition is widespread and above all highly popular in official economic policy and official environmental policy. It may be encountered in many official documents. The proposition is disputable for the following reasons.

Firstly, environmental deterioration is precisely the consequence of growth of production. The production growth attained is largely the result of increases in productivity, in which the loss of scarce environmental goods has not been taken into account. In fact, in this process environment is largely substituted for labour (and capital) and assigned a zero value. Few people are aware of the following. About a quarter to one third of the activities going to make up national income do not contribute to its growth, because by definition no increase in productivity can result from them. In another part the improvements in productivity are only slight. The growth of at least $3 \%$ a year (a doubling of production in 23 years) desired by official policy must therefore be achieved by much higher growth percentages among the remaining activities. Unfortunately, these are precisely the activities which, by use of space or pollution, in production or consumption, do the greatest harm to the environment, such as the oil and petrochemical industries, agriculture, public utilities, roadbuilding and the extraction of minerals $(9)$.

Secondly, restoration after the event is usually much to very much more expensive than behaviour in which, in the perfomance of the activities of production and consumption, allowance is made for the environment. In the Netherlands, the poisoning of the soil by industrial chemical wastes could have been prevented at the cost of several hundred million Dutch guilders. Restoration costs are now estimated at 10-20 billion guilders. Other well-known examples are reforestation, restoration of eroded land etc... Behaviour that spares the environment does, however, restrain production growth at the moment.

Thirdly, a number of environmental losses are irreparable.

Environmental conservation is in essence a matter of reallocation: the scarce factor of production environment, which has been incorrectly treated as a free good, must be charged for. The shift in factors of production that this requires must, if we desire a sustainable economy, take place on the spot, and not after the event by restoration. The reasoning that production must grow to create scope for conservation of the environment is disputable and dangerous. It amounts to the recommendation to fell most of a forest in order to conserve the remnants with the money earned. Disproving the proposition removes a stumbling block to a good environmental policy. 


\section{Concluding remarks}

This paper is principally concerned with the economic context of the use of environmental data: fitting statistical environmental data into economic planning (see Introduction). The theoretical comments that have been made on this apply in principle, in my opinion, to both industrialized and developing countries. However, the practical problems in poor and rich countries differ considerably.

The present author considers the environmental problems in the poor countries to be much more serious and urgent than in the rich ones, above all through erosion(10). As a result of the poverty the margins for choice are narrower, while at the same time the consequences of burdening the environment are already being personally experienced much more strongly. In these circumstances thoughts soon go to a greater emphasis in development co-operation on conservation of essential things such as pure water, forests on hillsides and fertile soil, in conjunction with a population policy. In the reasoning in the World Conservation Strategy, survival and conservation of nature and environment run largely parallel. The present author agrees with the argumentation on which this reasoning is based.

The bottlenecks in the information are to be found in lack of data, lack of skilled personnel and lack of methodology, among others. The incentives to overcome these constraints are of course an extension of the incentives for the conservation of soil condition and of other resources. These incentives have been discussed above; they consist of the desire not to be even worse off presently as a result of degradation of resources for the sake of short-term solutions. Furthermore, the knowledge that prevention is usually much less expensive than restoration can be an important incentive. As stated, in essence the problem in the various parts of the world do not differ, but the margins are much narrower in poor countries and the choices consequently more painful. Perhaps development co-operation can extend to the financing of the acquisition of more information for decisions on the environment, as a first step towards a good environmental policy in developing countries.

\section{Notes}

(1) See for the cost-benefit analysis of the salination of the Rhine: Hueting, R. Some economic aspects of pollution of the Rhine. In: Rhine Pollution; Legal, economic and technical aspects (Hueting, R., Van der Veen, C., Kiss, A.Ch., Jessurun d'Oliveira, H.U.). Zwolle, 1978. See for corrections to national income; Hueting, R., 1980a.

(2) For a more extensive argumentation see inter alia Robbins, L. An Essay on the Nature and Significance of Economic Science, Second Edition, London, 1952; Hennipman, P. Welvaartstheorie en economische politiek. Alphen aan den Rijn, Brussels, 1977; Hueting, R. 1980a.

(3) See for a complete description: Hueting, R., 1980a.

(4) A list of these hazards is to be found in: Hueting, R. Results of an economic scenario that gives top priority to saving the environment and energy instead of encouraging production growth. In: Economic Growth and the Role of Science (Bergström, S. ed). Edsbruk, Sweden, 1984.

(5) C.B.S. Facetten van economische ontwikkeling (Facets of Economic Development). The Hague, 1983. In the title the term "economic development" has been deliberately opted for instead of the term "economic growth". (6) A fuller explanation of the use of satellite accounts can be found in: Theys, J. Environmental Accounting and Its Use in Developing Policy. Paper prepared for the Environmental Accounting Workshop, organized by UNEP and hosted by the World Bank, Washington, D.C., 5-8 November 1984.

(7) Examples of the different cases that can occur in practice are elaborated, with the aid of fictitous figures, in: Hueting, R. Framework for a cost-benefit analysis for different uses of a humid tropical forest area. Paper prepared for the Trompenbos seminar d.d. 22-24 September 1986 at Baarn.

(8) This argument has been elaborated by the author in a number of articles and supported by examples. See inter alia: Hueting, R. Socio-Economic Effects of Environmental Policy. Paper prepared for the Symposium on Quality of Life. Universidad de Deusto, Bilbao, 21-23 September 1977.

(9) This emerges from an analysis of the base material for the Netherlands National Accounts (of which the sectorial composition does not differ appreciably from that of the UK) over the period 1965-1979. See Hueting, R. Some comments on the report "A low Energy Strategy for the United Kingdom", compiled by Gerald Leach et al. for the International Institute for the Environment and Development (IIED). Paper prepared for the Working Party on Integral Energy Scenarios. The Hague, 20 May 1981.

(10) See inter alia: Brown, L.R. et al. State of the World 1984. New York, London, 1984.

\section{References}

ECE. Statistical Commission and Economic Commission for Europe. Conference of European Sratisticians. Report of the Meeting held in Geneva, 19-23 March 1973, CES/AC, 40/5, p. 13, 1973. 
Hueting, R. New Scarcity and Economic Growth. Amsterdam, New York, Oxford, North Holland Publishing Company, 1980a.

Hueting, R. The Use of Environmental Data in the Economic Decision-Making Process. Paper prepared for the Seminar on Methodological Problems of Environmental Statistics under the joint auspices of the Conference of European Statisticians of the ECE and the Senior Advisors to ECE Governments on Environmental Problems, Warsaw, 1619 September 1980.

Hueting, R. A Note on the Construction of an Environmental Indicator in Monetary Terms as a Supplement to National Income with the Aid of Basic Environmental Statistics, 1986.

Kuznets, S. National Income and Industrial Structure. In: The Econometric Society Meeting, September 6-18, 1947, Washington D.C., Proceedings of the International Statistical Conferences, Volume V. Calcutta, undated, p. 205, 1947.

Kuznets, S. On the Valuation of Social Income. Economica, February/May, 1948. 